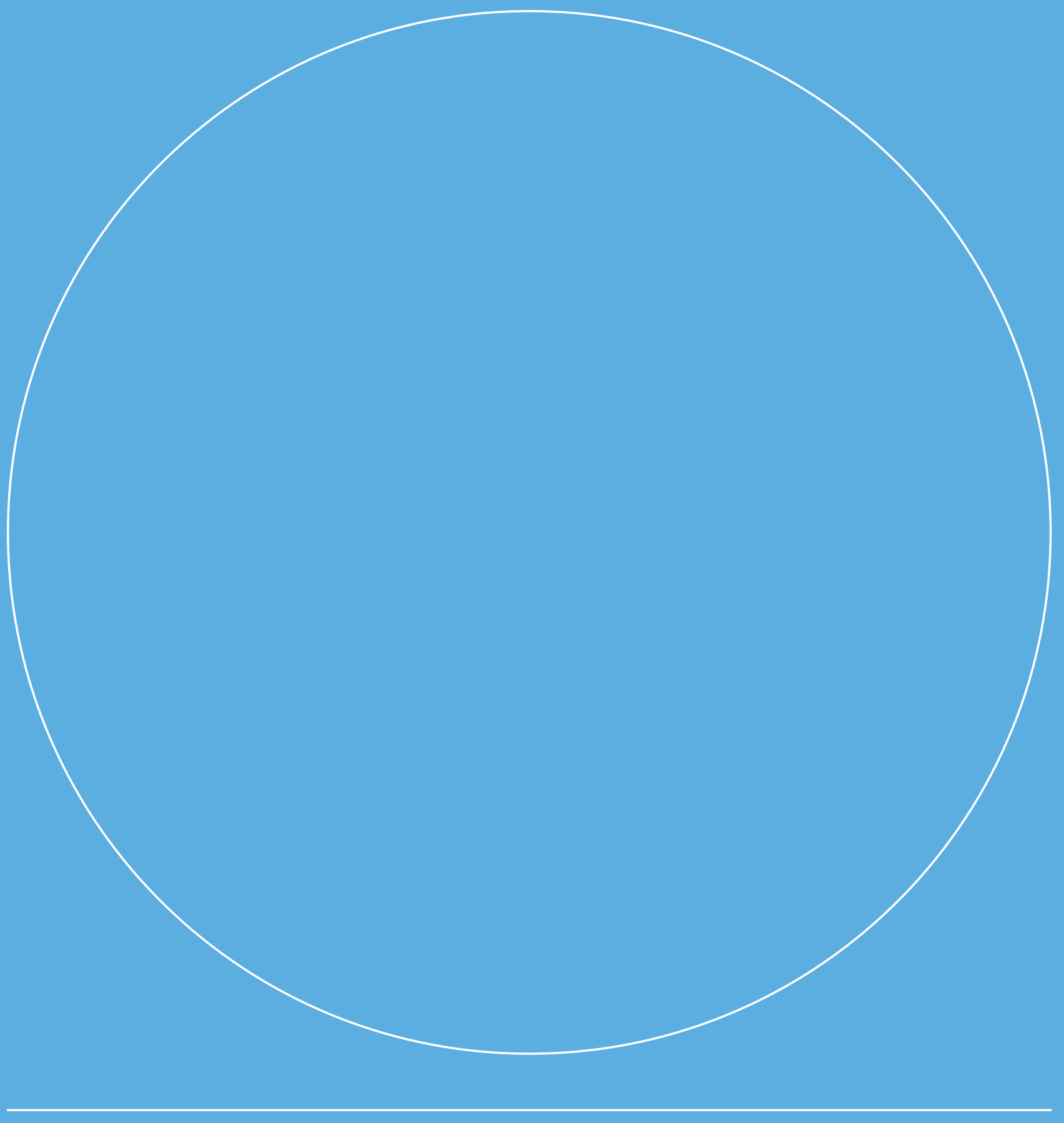

\title{
Bamboo composites
}

E.R.P. Keijsers 



\section{Bamboo composites}

Authors: E.R.P. Keijsers

This research project has been carried out by Wageningen Food \& Biobased Research.

Wageningen Food \& Biobased Research

Wageningen, March 2020

Public

Report 2084

ISBN 978-94-6395-523-2 
Version: final

Reviewer: J.E.G. van Dam

Approved by: J.M. Jetten

This report can be downloaded for free at https://doi.org/10.18174/530197/ or at www.wur.eu/wfbr (under publications).

(C) 2020 Wageningen Food \& Biobased Research, institute within the legal entity Stichting Wageningen Research.

The client is entitled to disclose this report in full and make it available to third parties for review. Without prior written consent from Wageningen Food \& Biobased Research, it is not permitted to:

a. partially publish this report created by Wageningen Food \& Biobased Research or partially disclose it in any other way;

b. (let a third party) use this report created by Wageningen Food \& Biobased Research or the name of the report or Wageningen Food \& Biobased Research in whole or in part for the purposes of making claims, conducting legal procedures, for (negative) publicity, and for recruitment in a more general sense;

c. use the name of Wageningen Food \& Biobased Research in a different sense than as the author of this report.

PO box 17, 6700 AA Wageningen, The Netherlands, T + 31 (0)317 4800 84, E info.wfbr@wur.nl, www.wur.eu/wfbr. Wageningen Food \& Biobased Research is part of Wageningen University \& Research.

All rights reserved. No part of this publication may be reproduced, stored in a retrieval system of any nature, or transmitted, in any form or by any means, electronic, mechanical, photocopying, recording or otherwise, without the prior permission of the publisher. The publisher does not accept any liability for inaccuracies in this report. 


\section{Contents}

$\begin{array}{ll}\text { Summary } & 4\end{array}$

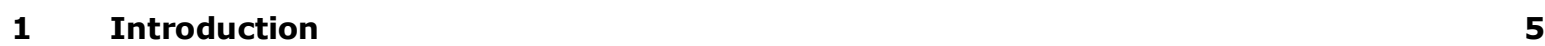

1.1 Biobased and circular economy 25

1.2 Production processes $\quad 5$

$\begin{array}{lll}1.2 .1 & \text { Injection moulding } & 5\end{array}$

$\begin{array}{lll}1.2 .2 & \text { Profile extrusion } & 6\end{array}$

$\begin{array}{lll}1.2 .3 & 3 \mathrm{D} \text { printing } & 7\end{array}$

2 Experimental $\quad 8$

2.1 Identification of waste plastic $\quad 8$

2.2 Bamboo $\quad 8$

2.3 Production and testing of bamboo composites 9

2.3.1 Compounding 9

2.3.2 Injection moulding $\quad 9$

2.3.3 Mechanical testing 9

3 Results $r$

3.1 Plastic waste 11

$\begin{array}{lll}3.2 & \text { Bamboo composites } & 11\end{array}$

$4 \quad$ Conclusions and recommendations $\quad 18$

$\begin{array}{lll}4.1 & \text { Use of Bamboo from Ethiopia } & 18\end{array}$

$\begin{array}{lr}4.2 & \text { Setup of a bamboo composite production facility } \\ \end{array}$

Annex $1 \quad$ Data mechanical testing

19 


\section{Summary}

This report describes the research that has been performed by Wageningen Food \& Biobased Research on the development of bamboo composites from Bamboo from Ethiopia. This research is part of the INBAR DUTCH-Sino program.

Currently the industry in Ethiopia is producing bamboo panels and bamboo stick based products blinds, tooth picks, incense sticks. Plastic composite panels would be a new option for bamboo products in Ethiopia. Based on existing knowledge of plastic composite production processes an overview of possible processes and plastics matrix material is given. Ideally, plastic waste streams from Ethiopia would be used as plastic matrix, however, the plastic polymer type of two major large waste streams, PET bottles and PE bags and foils is considered not suited as plastic matrix for plastic fibre composites.

Lab-scale tests have been performed on fine and course residues from current bamboo stick industry (based on highland and lowland bamboos) and on milled samples from top, middle and bottom parts of highland and lowland bamboo. Injection moulded composites were produced base on 30wt\% of bamboo combined with a commercial grade polypropene (67 wt\%) and a commercial coupling agent (3 wt\%). Mechanical testing results show that all types of bamboo sources can be used to produce composites. On average, the composites of highland bamboo had slightly lower mechanical properties than lowland bamboo. The bending stiffness of the fine and course residues was slightly lower than the unprocessed bamboo samples. However, differences are small.

Some considerations and recommendations concerning the development of bamboo composite panels are made, highlighting the differences with the current bamboo stick industry in Ethiopia. Current industry is labour intensive and the process is robust, the processes can be halted and restarted at any moment, water content/dryness of the bamboo is not extremely critical. The production process for bamboo composites is capital intensive. The process should be run continuously to prevent losses on start-up and shut down. Moisture content of the fibres needs to be controlled, ideally production should be performed under climate controlled conditions in the work space. 


\section{Introduction}

\subsection{Biobased and circular economy}

In Ethiopia bamboo based panels are currently made from bamboo strips that are glued together with resin. A shift towards a bamboo composite material made partly from bamboo and partly from a plastic matrix material will allow for different designs and will appeal to a lot of consumers. However this shift will also affect the biobased content of the product and the possibilities to reuse or recycle the products. In the transition towards a biobased and circular economy the choice of plastic matrix will be worth considering. In this report we focussed on composites made of fibres and thermoplastic polymers. Thermoplastic polymers can be recycled after use, although some properties are deteriorated. The options to use waste plastic as plastic matrix are considered.

Thermoplastic materials can be biobased and/or biodegradable. Biodegradable plastics are not considered here, because panels will be designed for a long use lifespan. Also the climate conditions of high temperatures and humidity will increase the speed of (bio)degradation. Currently, the availability of biobased thermoplastic materials (e.g. PLA) is limited and costs are relatively high. Therefore, in this report we focussed on fibre reinforced composites of bamboo and polypropene (PP). Polyethene thermoplastics (PE) based compositesmay also be an option.

\subsection{Production processes}

Three different production processes can be used to produce bamboo composite panels and products.

\subsubsection{Injection moulding}

In the injection moulding process a mixture of fibres and a thermoplastic matrix material is injected under high pressure into a closed mould. The mixture is called a compound and is produced on larger

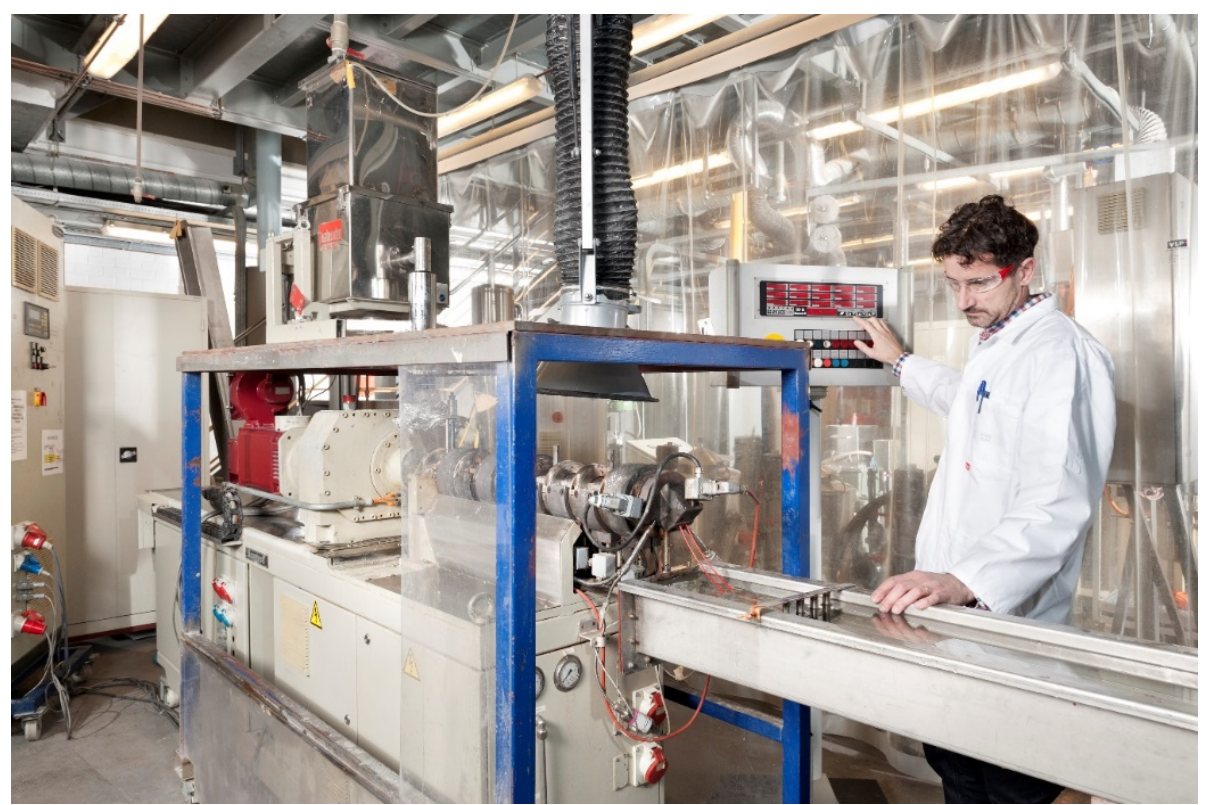

Figure 1. Extrusion compounding (filaments) [WFBR]

scale by extrusion. During compounding the thermoplastic material is melted and mixed with the fibres. After cooling pellets or filaments are produced. A wide variety of different objects can be produced by using different moulds. 


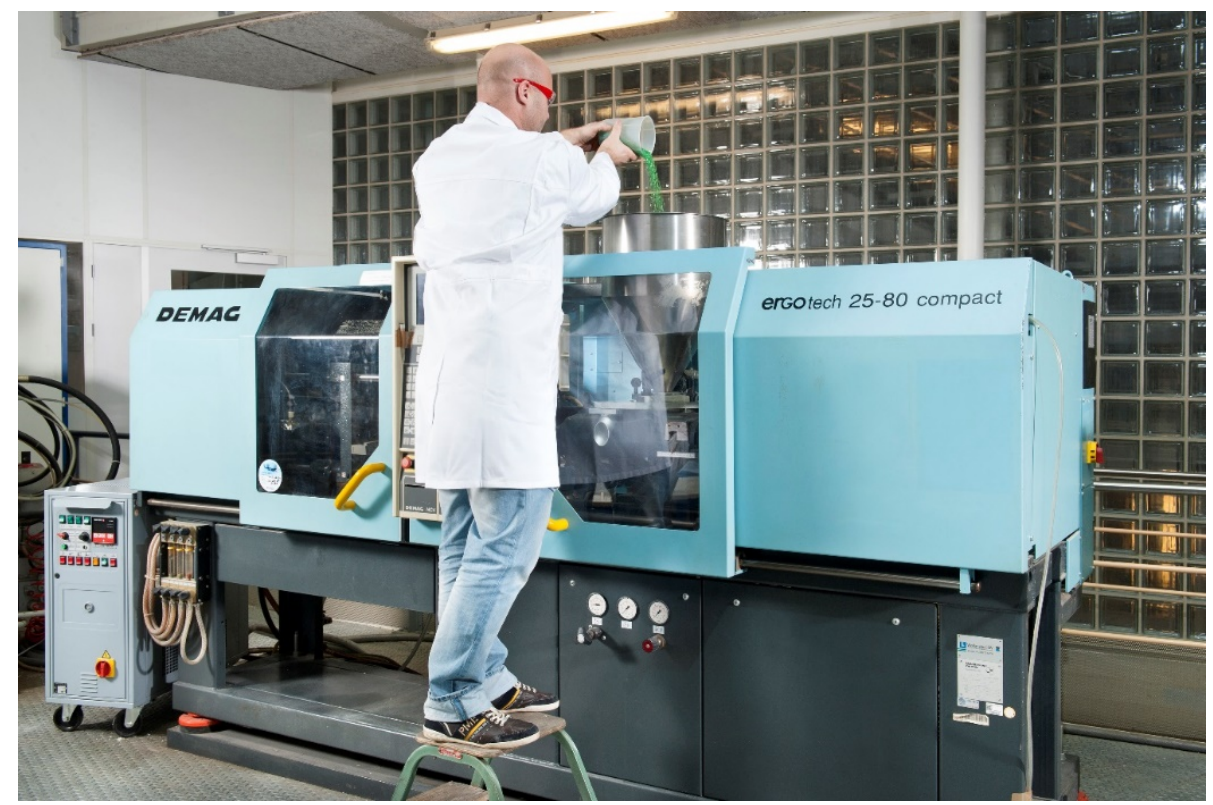

Figure 2. $\quad$ An injection moulding machine for small objects [WFBR]

\subsubsection{Profile extrusion}

Profile extrusion is a process that uses extrusion to produce a continuous profile from fibre filled compounds. The pressure in the process is lower than during injection moulding and the design of the products is less complex. Most panels and profiles from fibre filled compounds are produced using profile extrusion. Most profile extrusion processes from non-wood fibre materials use a two stage process. First pellets are produced using a compounding extrusion process, secondly profiles are produced using a profile extruder. Wood based profiles can be produced in a single stage process. Wood chips and thermoplastics are introduced in an extruder that mixes the components and produces the profile in a single run. This single stage process is more cost effective, however less versatile. Separating the compounding and profile extrusion stage can be a good choice. Compounding 
can be performed on a different location, compounded pellets can be sold as intermediate product. Pellets can be stored for longer periods without degradation of properties.

\subsubsection{D printing}

Compounds in the form of pellets or fillaments can also be used in 3D printers. Different shapes can be produced layer for layer. Larger and smaller objects are possible.

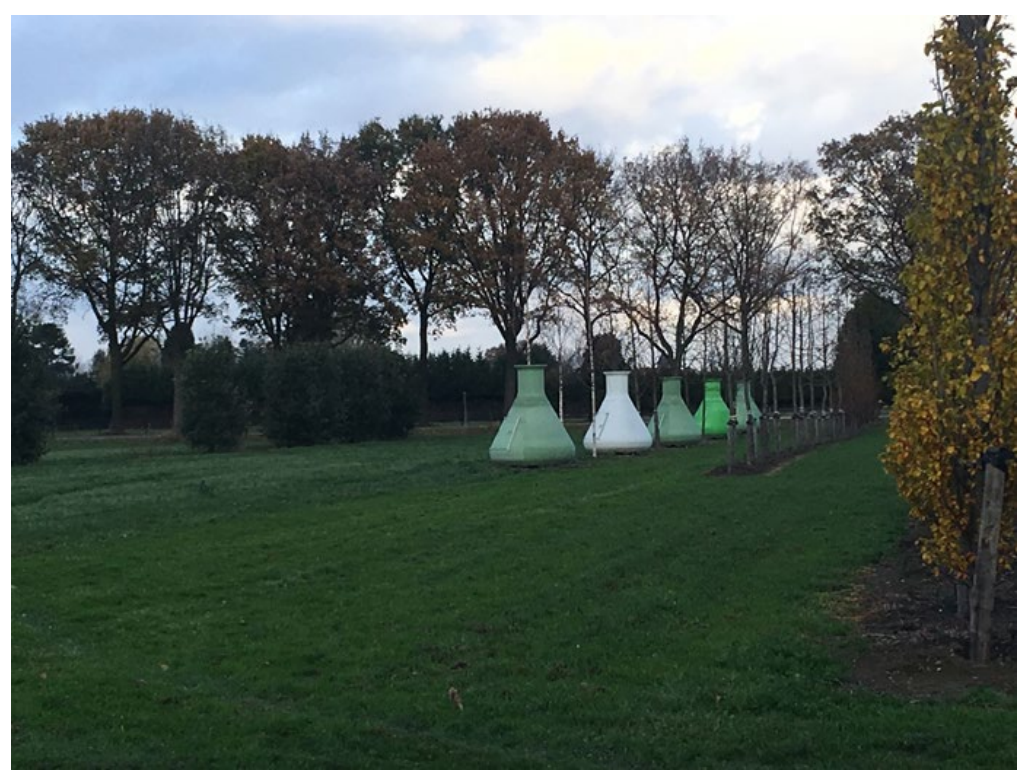

Figure 3. Large size 3D printed objects (erlenmeyers) [WFBR]

Production costs are still high, mainly because of the slow production process, however the design of the product can be changed easily and at low cost compared to profile extrusion and injection moulding.

\subsection{Bamboo polymer composites}

In this report two different bamboo types that are abundant in Ethiopia, highland (Yushania alpina) and lowland (Oxytentra abyssinica) bamboo are used. Besides samples of the top, middle and bottom of these bamboo poles, residues from the bamboo stick production process are used, a coarse and a fine residu. As thermoplastic polymer a commercially available polypropene grade is used (Sabic 520P), additionally a commercial coupling agent is added (Eastman G3015). The coupling agent ensures the bonding between the hydrophobic PP and the hydrophylic bamboo fibres. In an industrial profile extrusion process other additives will be added, e.g. colouring agents, waxes etc. On industrial scale bamboo content can be up to 50-70wt\%. In this research injection moulding was performed, limiting the bamboo content of the compound. 


\section{Experimental}

\section{$2.1 \quad$ Identification of waste plastic}

The main component of the supplied recycled plastics was determined using a sIRo, Stationary InfraRed optic device from IoSYS individual optical systems. This method uses a near infrared light source and Nir spectrometer optics combined with a database to identify plastics.

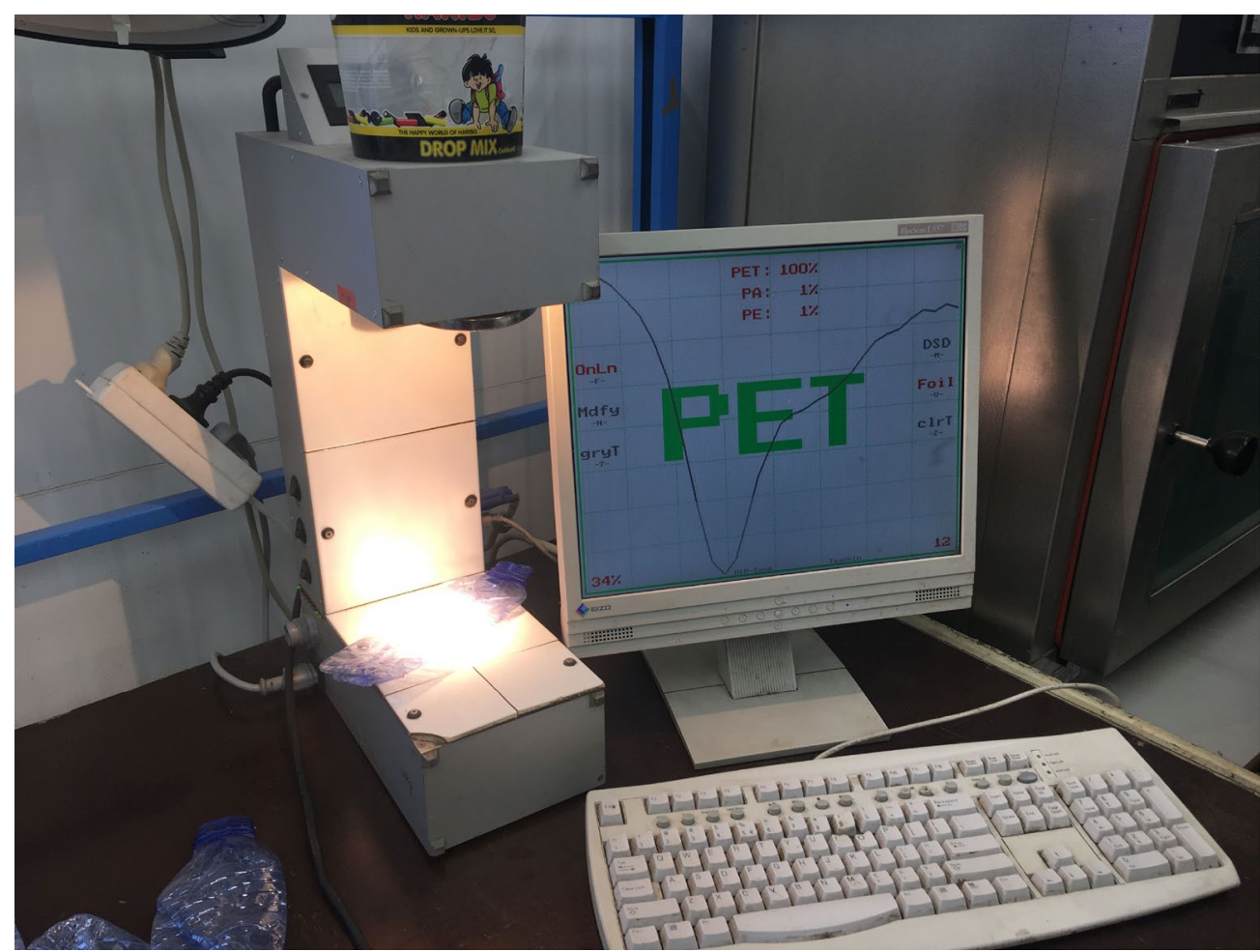

Figure 4. SIRo equipment to establisch the type of plastic [WFBR]

\subsection{Bamboo}

The unprocessed bamboo samples were milled to $1-2 \mathrm{~cm}$ long pieces using a cutting mill. After this first cutting stage a second cutting stage was performed using a lab-scale Retch cutting mill. A sieve with holes of $1 \mathrm{~mm}$ was used to obtain finely cut materials.

The coarse and fine residues were cut in a single stage using a lab-scale Retch cutting mill. A sieve with holes of $1 \mathrm{~mm}$ was used to obtain finely cut materials. 


\subsection{Production and testing of bamboo composites}

\subsubsection{Compounding}

Compounds of 30wt\% milled and dried bamboo, 67 wt $\%$ PP and 3\% coupling agent were produced using a Haake kneader.

Table 1. Parameters for the mixing of polymer and fibres

\begin{tabular}{lr}
\hline Haake kneader & \\
\hline Temp. $\left[{ }^{\circ} \mathrm{C}\right]$ & 200 \\
Speed [rpm] & 100 \\
Batch weight [gram] & 250 \\
Total Mixing time [min] & 10 \\
Polymer mixing time [min] & 3 \\
Adding fibers [min] & $3-6$ \\
Remaing mixing time [min] & 4 \\
\hline
\end{tabular}

\subsubsection{Injection moulding}

Injection moulding as shown in Figure 2 was performed to obtain test bars for three point bending tests and impact tests.

Table 2. Parameters for the injection moulding of polymer and fibres

\begin{tabular}{lc}
\hline Injection moulder & Demag IntElect 75-250 \\
\hline Temp profile $\left[{ }^{\circ} \mathrm{C}\right]$ & $40|190| 200|200| 200$ \\
Mould temp. $\left[{ }^{\circ} \mathrm{C}\right]$ & 30 \\
Holding pressure [bar] & 400 \\
Holding time $[\mathrm{s}]$ & 10 \\
Cooling time $[\mathrm{s}]$ & 20 \\
Dosing speed $[\mathrm{rpm}]$ & 200 \\
Injection speed $[\mathrm{mm} / \mathrm{s}]$ & 60 \\
\hline
\end{tabular}

\subsubsection{Mechanical testing}

After injection moulding the produced test bars were stored at controlled climatic conditions for more than 5 days for conditioning.

Mechanical properties (three point bending, Figure 5) were measured using a Zwick Z010 all-round line $10 \mathrm{kN}$ mechanical testing machine according to ISO 527-1. Samples were prepared according to ISO 527-2. E-Modulus test speed was $1 \mathrm{~mm} / \mathrm{min}$, Test speed until break was $10 \mathrm{~mm} / \mathrm{min}$.

Charpy Unnotched impact resistance was measured according to ISO 179 using a Ceast impact tester. Samples were prepared according to ISO 294-1, Maximum Energy was 4J. 


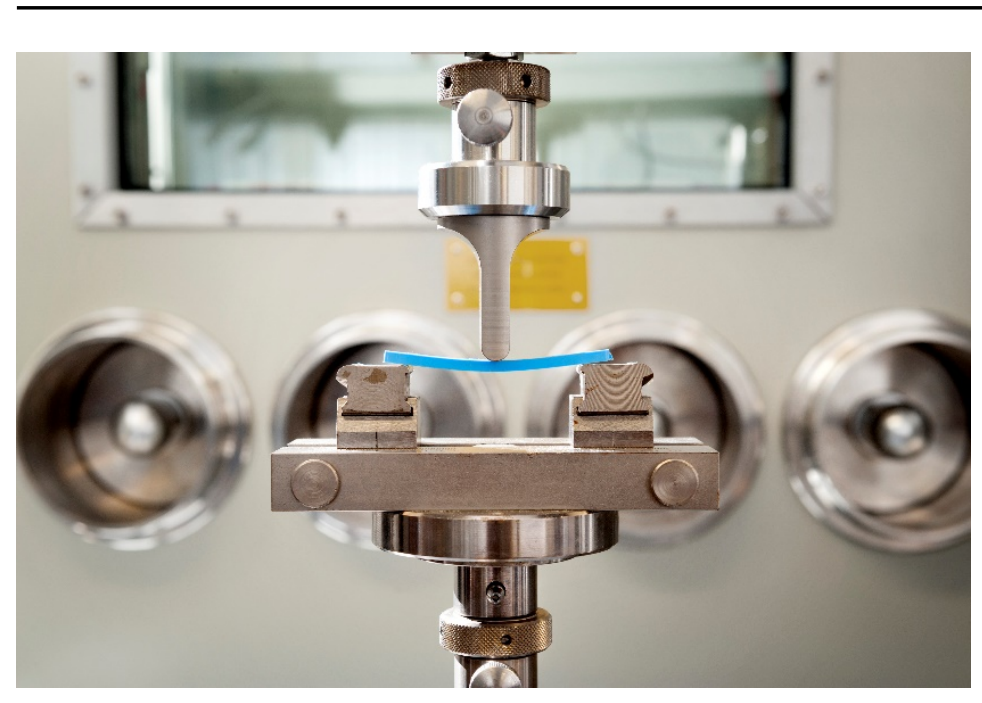

Figure 5. Three point bending test [WFBR] 


\section{Results}

\subsection{Plastic waste}

Two types of plastic waste were obtained from Ethiopia.

- The bottles were tested to be composed of PET as was expected because of the labels present on the bottles. PET is not suitable for the production of bamboo composites. PET is a thermoplastic material, however natural fibres like bamboo will deteriorate at the temperature necessary to process PET ( $>250^{\circ} \mathrm{C}$ ).

- The bags and foils were tested to be mainly composed of PE, however the type of PE present in bags and foils is not suited for the production of bamboo composites (The melt flow index is too low). PE for profile extrusion or injection moulding should have different properties.

\subsection{Bamboo composites}

After milling and drying the bamboo samples were kneaded. The processing parameters are given in Table 3. Only minor differences in melt temperature and torque were observed.

Table 3. Processing parameters during kneading of bamboo composites

\begin{tabular}{|c|c|c|c|}
\hline Sample & Composition & $\begin{array}{c}\text { Melt temperature } \\
{\left[{ }^{\circ} \mathrm{C}\right]}\end{array}$ & $\begin{array}{c}\text { Torque } \\
\text { [Nm] }\end{array}$ \\
\hline 110220-I & 67\% Sabic 520P, 3\% Eastman G3015, 30\% Lowland fine & 187 & 32 \\
\hline $110220-\|$ & 67\% Sabic 520P, 3\% Eastman G3015, 30\% Lowland coarse & 173 & 33 \\
\hline 110220-III & 67\% Sabic 520P, 3\% Eastman G3015, 30\% Lowland bottom & 174 & 33 \\
\hline 110220-IV & 67\% Sabic 520P, 3\% Eastman G3015, 30\% Lowland middle & 170 & 31 \\
\hline $110220-V$ & 67\% Sabic 520P, 3\% Eastman G3015, 30\% Lowland top & 172 & 30 \\
\hline $110220-\mathrm{VI}$ & 67\% Sabic 520P, 3\% Eastman G3015, 30\% Highland fine & 179 & 29 \\
\hline 110220-VII & 67\% Sabic 520P, 3\% Eastman G3015, 30\% Highland coarse & 180 & 33 \\
\hline 110220-VIII & 67\% Sabic 520P, 3\% Eastman G3015, 30\% Highland bottom & 179 & 31 \\
\hline $110220-I X$ & 67\% Sabic 520P, 3\% Eastman G3015, 30\% Highland middle & 175 & 28 \\
\hline $110220-X$ & 67\% Sabic 520P, 3\% Eastman G3015, 30\% Highland top & 175 & 32 \\
\hline
\end{tabular}

After kneading the compounds were crushed into smaller pieces and injection moulded. The main injection moulding parameter, injection pressure is shown in Table 4. Only minor differences in injection pressure of the compounds were observed.

Table 4. Processing parameters during injection moulding of bamboo composites

\begin{tabular}{lcc}
\hline Sample & Composition & Injection pressure [bar] \\
\hline Sabic 52OP & 100\% Sabic 520 P & 446 \\
$110220-\mathrm{I}$ & 67\% Sabic 520P, 3\% Eastman G3015, 30\% Lowland fine & 258 \\
$110220-\mathrm{II}$ & $\mathbf{6 7 \%}$ Sabic 520P, 3\% Eastman G3015, 30\% Lowland coarse & 245 \\
$110220-\mathrm{III}$ & $\mathbf{6 7 \%}$ Sabic 520P, 3\% Eastman G3015, 30\% Lowland bottom & 256 \\
$110220-\mathrm{IV}$ & $\mathbf{6 7 \% ~ S a b i c ~ 5 2 0 P , ~ 3 \% ~ E a s t m a n ~ G 3 0 1 5 , ~ 3 0 \% ~ L o w l a n d ~ m i d d l e ~}$ & 256 \\
$110220-\mathrm{V}$ & $\mathbf{6 7 \%}$ Sabic 520P, 3\% Eastman G3015, 30\% Lowland top & 244 \\
$110220-\mathrm{VI}$ & $\mathbf{6 7 \% ~ S a b i c ~ 5 2 0 P , ~ 3 \% ~ E a s t m a n ~ G 3 0 1 5 , ~ 3 0 \% ~ H i g h l a n d ~ f i n e ~}$ & 246 \\
$110220-\mathrm{VII}$ & $\mathbf{6 7 \% ~ S a b i c ~ 5 2 0 P , ~ 3 \% ~ E a s t m a n ~ G 3 0 1 5 , ~ 3 0 \% ~ H i g h l a n d ~ c o a r s e ~}$ & 252 \\
$110220-\mathrm{VIII}$ & $\mathbf{6 7 \% ~ S a b i c ~ 5 2 0 P , ~ 3 \% ~ E a s t m a n ~ G 3 0 1 5 , ~ 3 0 \% ~ H i g h l a n d ~ b o t t o m ~}$ & 241 \\
$110220-\mathrm{IX}$ & $\mathbf{6 7 \% ~ S a b i c ~ 5 2 0 P , ~ 3 \% ~ E a s t m a n ~ G 3 0 1 5 , ~ 3 0 \% ~ H i g h l a n d ~ m i d d l e ~}$ & 257 \\
$110220-\mathrm{X}$ & $\mathbf{6 7 \% ~ S a b i c ~ 5 2 0 P , ~ 3 \% ~ E a s t m a n ~ G 3 0 1 5 , ~ 3 0 \% ~ H i g h l a n d ~ t o p ~}$ & 248 \\
\hline
\end{tabular}


Examples of the produced test bars are shown in Figure 6. The PP without fibre is transparant. Bamboo filled PP is dark brown, as most fibre filled PP products. The products from the fine residues are slightly less dark. On close up (Figure 7), fibres can be seen inside the surface of the products.

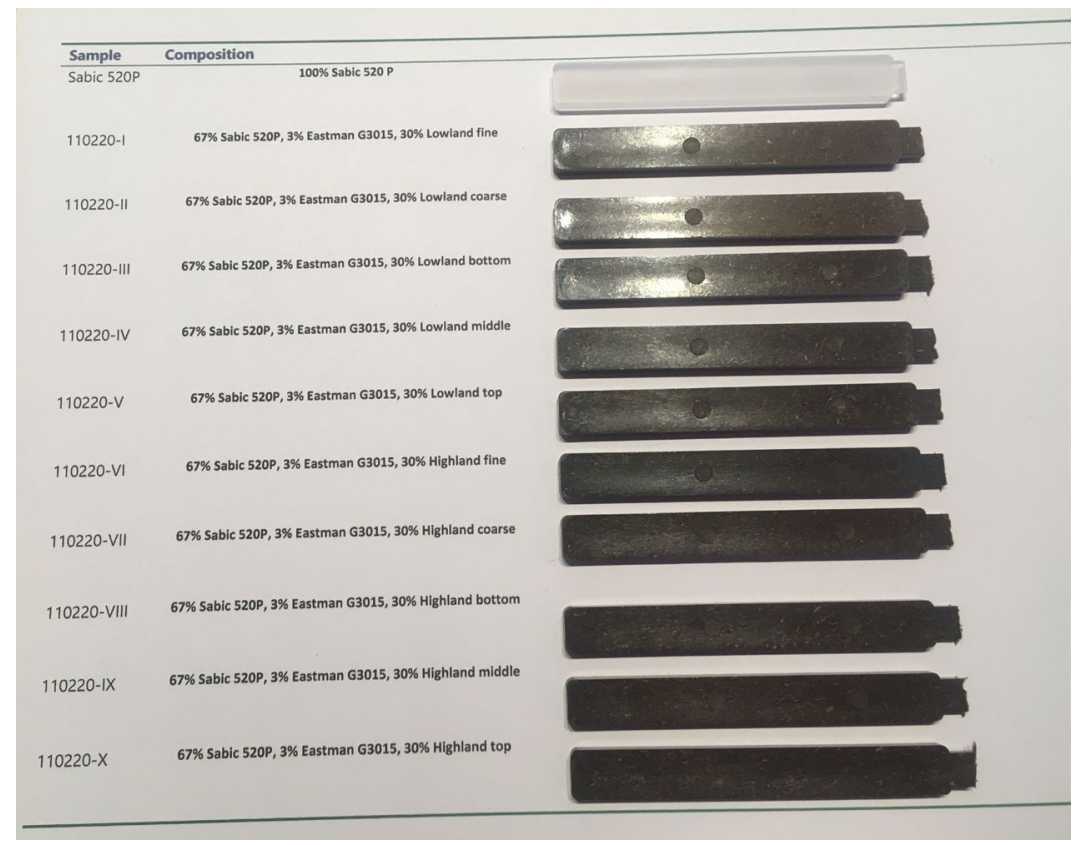

Figure 6. Picture of the different bamboo composites [WFBR]

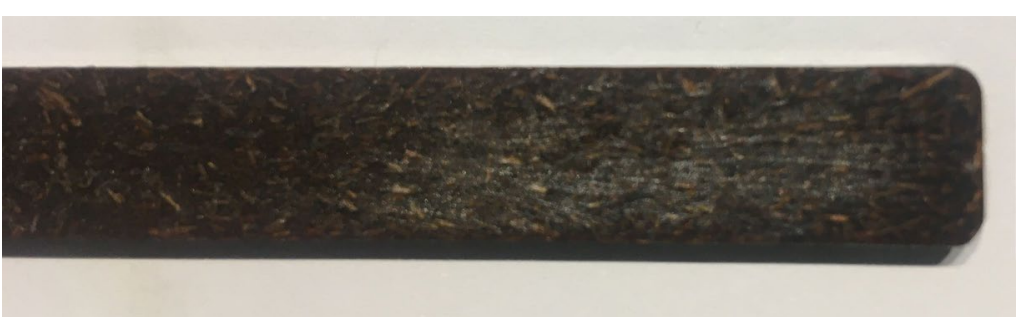

Figure 7. Surface of an injection moulded bamboo composite [WFBR]

All results of the mechanical testing of the composites are given in Appendix 1 . In Figure 8 the bending stiffness of the different composites is shown. As expected the bamboo fibres increase the bending stiffness compared to the PP without fibers. It can be observed that the stiffness of the highland bamboo samples is slightly lower when compared to the lowland bamboo samples. The fine residue samples resulted in lower stiffness, the coarse residue sample stiffness is comparable to the samples from the unprocessed bamboo. 


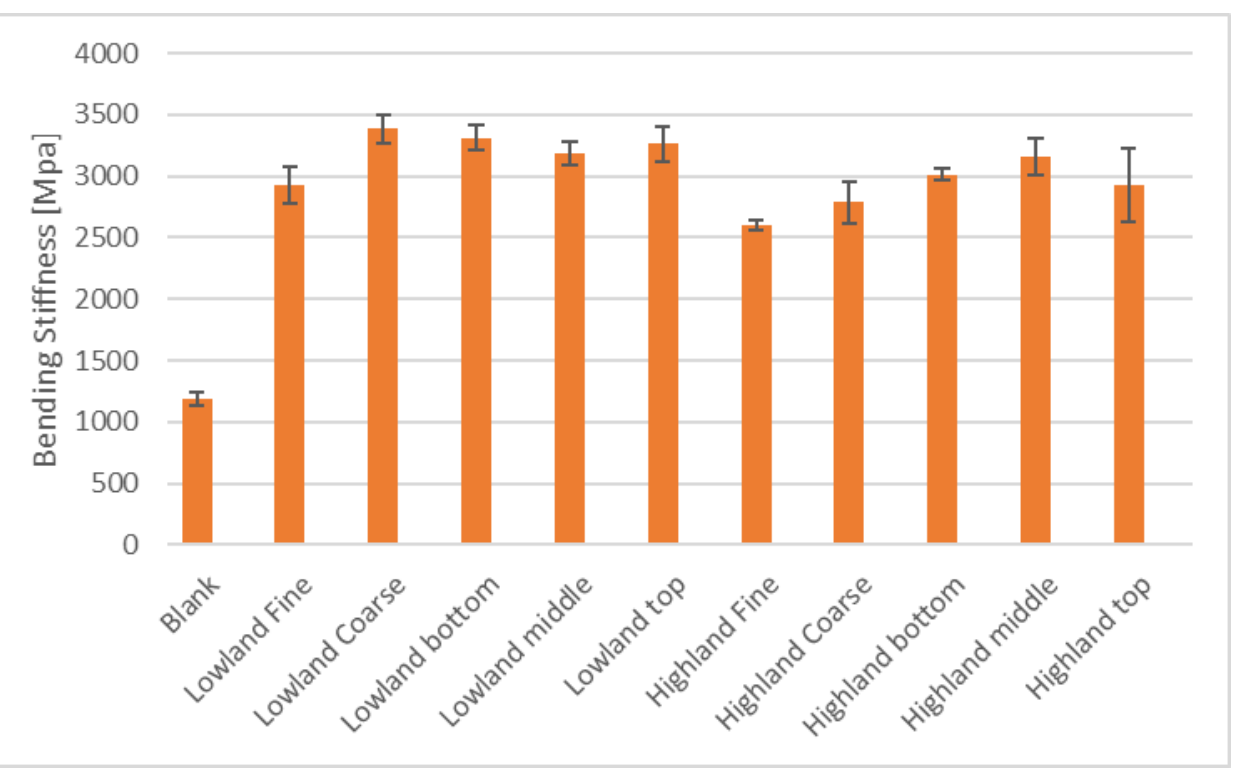

Figure 8. Bending stiffness of bamboo composites, $30 w t \%$ bamboo.

The bending strength of the composites is shown in Figure 9. Bending strength of the bamboo filled composites is increased compared to the polypropyleen without fibres. Differences between the bamboo samples is small. Strength of the composites with highland bamboo is slightly lower than with lowland bamboo. The difference between residues and unprocessed bamboo is less clear.

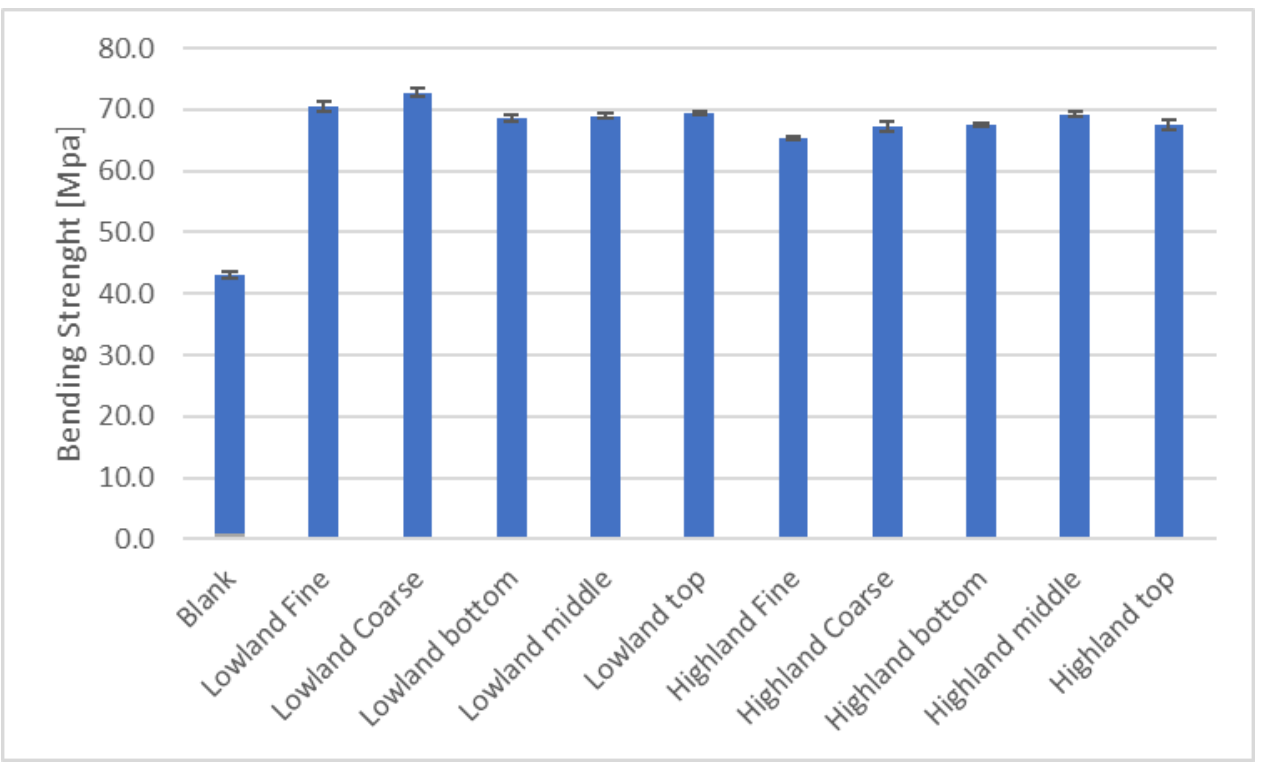

Figure 9. $\quad$ Bending strength of bamboo composites, 30wt\% bamboo.

Impact strength of the composites is given in Figure 10 and Figure 11. As expected the impact strength of the virgin polypropene is much higher than the impact strength of fibre filled polypropene. 


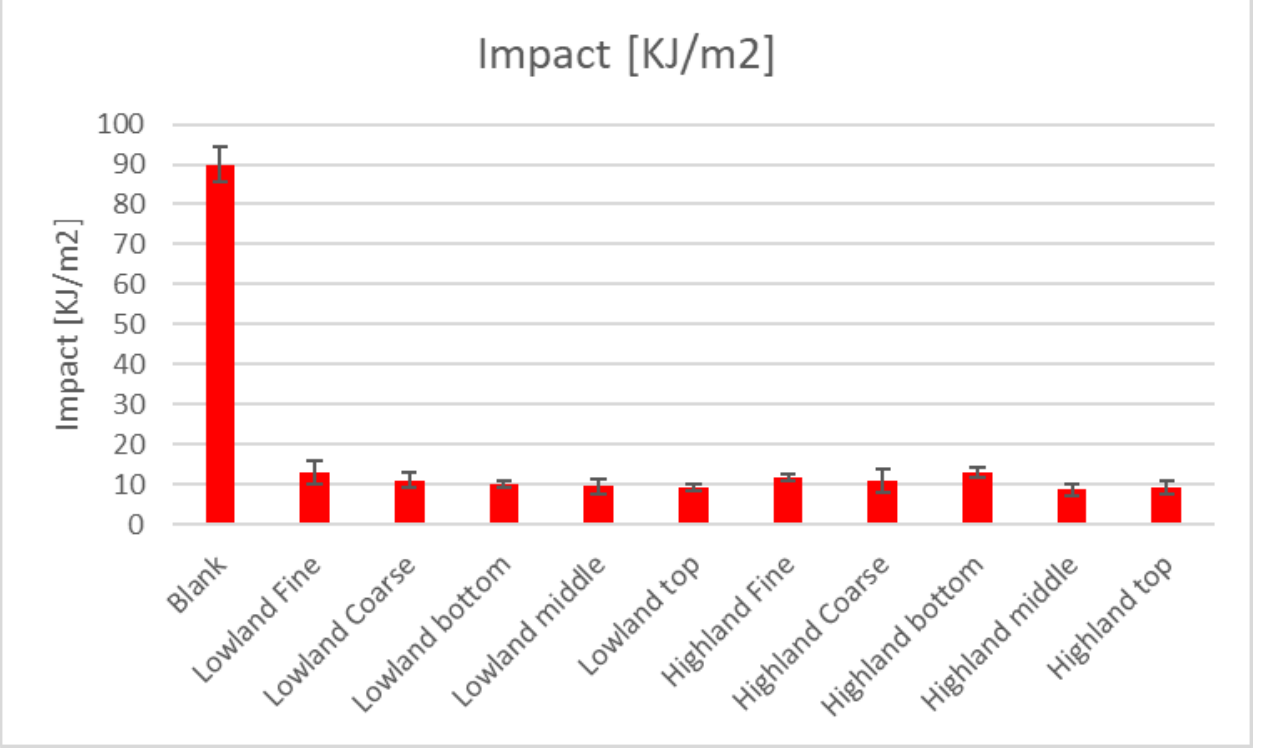

Figure 10. Charpy impact strength (unnotched) of bamboo composites, $30 w t \%$ bamboo

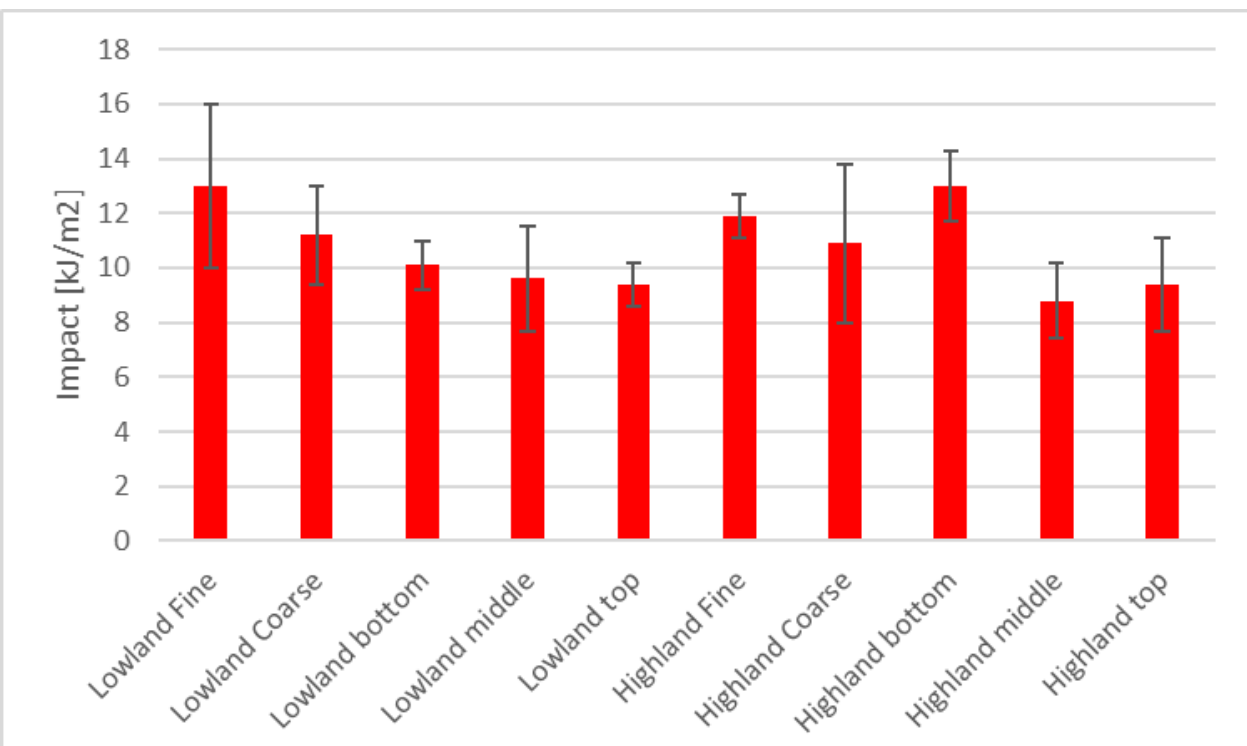

Figure 11. Charpy impact strenght (unnotched) of bamboo composites (excluding blank), $30 w t \%$ bamboo

Figure 11 shows that the variability of measurement for impact strength of fibre filled composed is relatively large compared to the actual value. No clear differences between the different bamboo samples can be observed. 


\section{Setup of a bamboo composite production facility}

The research has shown that the bamboo originating in Ethiopia can be used to produce bamboo composites. To produce profiles the profile extrusion technology can be used. Smaller parts can be produced using injection moulding. A bamboo composite/ panel production facility based on bamboo and PP will include several processing stages:

- Milling and drying of the bamboo

- Extrusion compounding of PP, coupling agent, bamboo and additives to increase processability, product performance (e.g. UV stability) and e.g. colorants.

- Profile extrusion

- Profile finishing (e.g. sawing)

After extrusion compounding the pellets or filaments can be stored. Pellets and filaments could also be sold as intermediate products for injection moulding or 3D printing.

A flow diagram of a processing facility is presented in Figure 12.

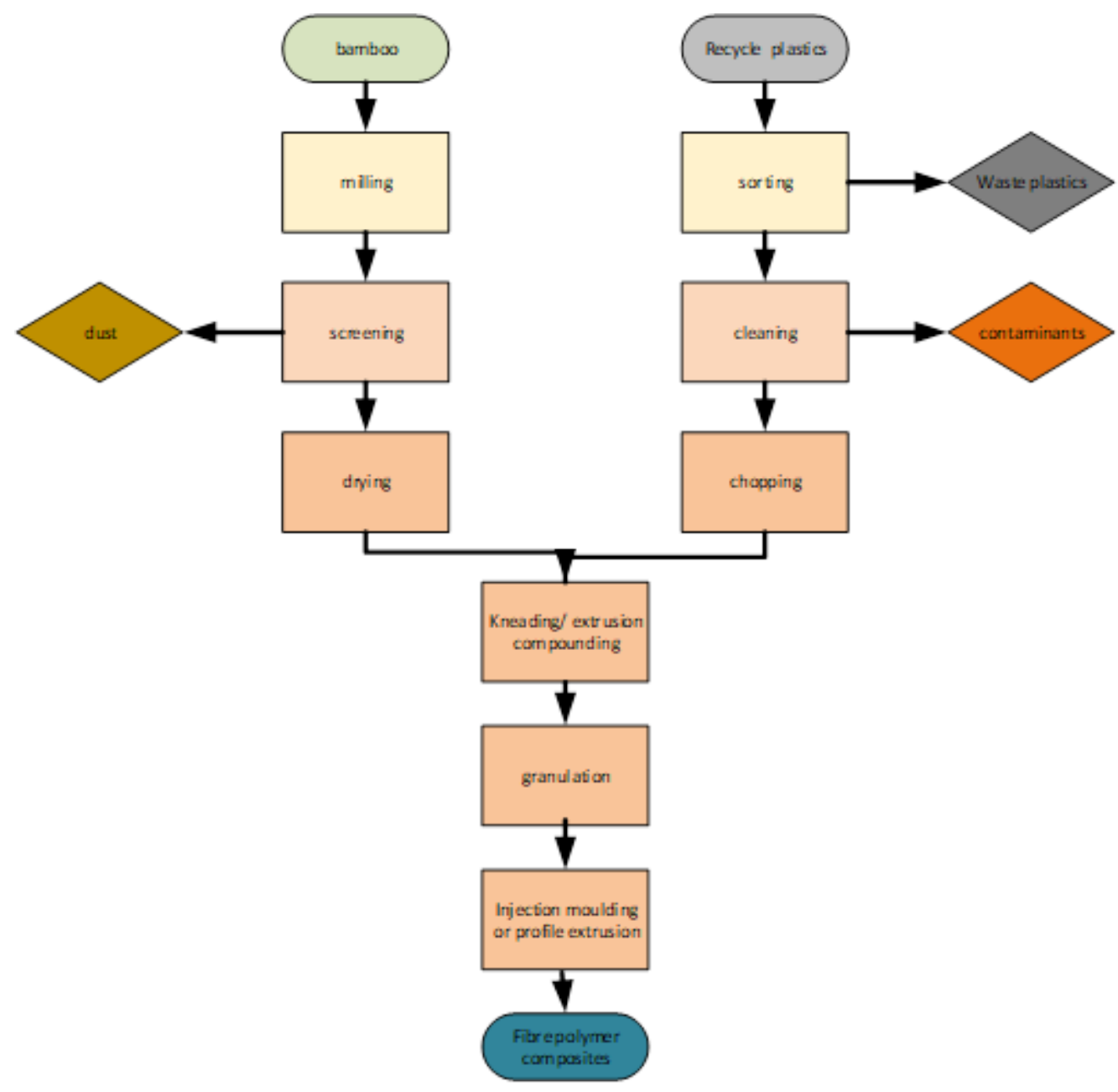

Figure 12. Flow diagram of a bamboo composite processing facility 
In comparison with the current bamboo stick industry several differences should be taken into account. The bamboo stick industry is labour intensive and the process is robust, the processes can be halted and restarted at any moment, water content/dryness of the bamboo is not extremely critical. The production process for bamboo composites is capital intensive. The process should be run continuously to prevent losses on start-up and shut down. Dryness of the fibres needs to be controlled, ideally production should be performed under controlled climatic conditions (constant temperature and humidity of the processing space).

\subsection{Use of recycled plastic}

The two types of recycled plastic tested (PET-bottles and PE films) are not suitable as raw material for profile extrusion or injection moulding in combination with bamboo fibres. Polypropene is a better choice, specifically polypropene used in thick walled products (compared to films/bags). Typical products that are made from suitable polypropene are $^{1}$ :

- Rigid Packaging: crates, bottles, and pots

- Consumer Goods: household products and consumer goods (housewares, furniture, appliances, luggage, toys etc.)

- Automotive Applications: Battery cases, bumpers, fender liners, interior trim, instrumental panels and door trims

- Industrial Applications: Polypropylene sheets are widely used in industrial sector to produce acid and chemical tanks, sheets, pipes and Returnable Transport Packaging (RTD)

- Medical Applications: Disposable syringes, petri dishes, intravenous bottles, specimen bottles, food trays, pans, pill containers, etc.

- $\quad$ Fibers and Fabrics

These products are not made from $100 \%$ pure PP. Polymer additives are often used, like clarifiers, flame retardants, glass fibers, UV stabilisers, minerals, lubricants and pigments to improve the physical and/or mechanical properties of PP. Some of these additives may also be required in producing bamboo-pp composites.

It should be noted that unless a very clean and homogenouos source of recycled PP can be found, the products from recycled PP in combinations with bamboo fibres will have a (very) dark colour.

Lab research should be performed to select suitable recycled PP sources. A supplier of the technology on industrial scale may help in selecting additives for optimal production performance.

1 https://omnexus.specialchem.com/selection-guide/polypropylene-pp-plastic

\subsection{Economic considerations}

The setup of a production unit to compete with the global market of e.g. bamboo flooring made from bamboo composites is outside the scope of this research. Main idea is the production of flooring, furniture and or building materials for the Ethiopian market from bamboo and recycled plastic. Typically the production would start on small scale. It is difficult to perform a valid economical assassment from the perspective of WFBR. Knowledge about the prices of equipement and other economic parameters to be used in Ethiopia is lacking. From a European perspective, two main production set-ups are feasible:

- Bamboo-PP composites as bulk pellets or filaments produced by compounding. These pellets or filaments could be sold to exiting injection moulding companies

- $\quad$ Final products: Bamboo-PP profiles or injection moulded products. These products can be sold directly to consumers 
A high end compounding extruder used to produce up to $100 \mathrm{~kg} /$ hour pellets will cost $500 \mathrm{k} €$. (Based on the costs of a Berstorff extruder owned by WFBR). However compounding extruders, complete profile extrusion lines and injection moulding equipment are offered at much lower prices on www.alibaba.com. WFBR has no experience in evaluating the offers from this website. Two (random, no recommendation) examples:

- In 2020 a complete compounding extruder for the production of bamboo-PP pellets is offered at 65-125 k€.

- In 2020 a profile extrusion line for the production of a wood polymer composite from wood waste and recycled plastic with a capacity of $150-240 \mathrm{~kg} / \mathrm{hour}$ is offered ${ }^{2}$ at $45 \mathrm{k} €$.

1 https://www.alibaba.com/product-detail/Jwell-PP-PE-fill-bamboo-powder_62205374715.htmI

2 https://www.alibaba.com/product-detail/WPC-extrusion-machinery-for-producing-WPC_62387033254.htm/

A solid economical evaluations of the prodcution costs and expected product revenues for the internal Ethiopian market will be necessary to establish the viability of these processes. 


\section{$5 \quad$ Conclusions and recommendations}

\subsection{Use of Bamboo from Ethiopia}

Lab-scale tests on samples of lowland and highland bamboo showed that both types can be used to produce bamboo-PP composites. Coarse and fine residues of the current bamboo stick industry can also be used to produce composites. On average the composites of highland bamboo had slightly lower mechanical properties than lowland bamboo. The bending stiffness of the fine and coarse residues was slightly lower than the unprocessed bamboo samples. However, differences are small. The bending strenght and stiffness of the produced bamboo composites and the impact strength are at the same level as other milled fibre composites [WFBR]. Two types of waste plastics, bottles and plastic bags and foils were tested for their applicability as thermoplastic matrix for compounds for panel production. However both waste types were considered not suitable.

\subsection{Setup of a bamboo composite production facility}

A bamboo composite/ panel production facility based on bamboo and PP will include several processing stages:

- $\quad$ Milling and drying of the bamboo

- Extrusion compounding of PP, coupling agent, bamboo and additives to increase processability, product performance (e.g. UV stability) and e.g. colorants.

- Profile extrusion

- $\quad$ Profile finishing (e.g. sawing)

After extrusion compounding the pellets or filaments can be stored. Pellets and filaments could also be sold as intermediate products for injection moulding or 3D printing.

In comparison with the current bamboo stick industry several differences should be taken into account. The bamboo stick industry is labour intensive and the process is robust, the processes can be halted and restarted at any moment, water content/dryness of the bamboo is not extremely critical. The production process for bamboo composites is capital intensive. The process should be run continuously to prevent losses on start-up and shut down. Dryness of the fibres needs to be controlled, ideally production should be performed under controlled climatic conditions (constant temperature and humidity of the processing space).

Next steps for the setup of a bamboo composite production facility would need to focus on the technoecomical evaluation of the proposed processes, accompanied with lab scale tests using different recycled polypropene sources. 


\section{Annex 1Data mechanical testing}

\begin{tabular}{|c|c|c|c|c|c|c|c|c|c|}
\hline \multirow{2}{*}{$\begin{array}{l}\text { Sample } \\
\text { Sabic 520P }\end{array}$} & \multirow{2}{*}{$\begin{array}{l}\text { Composition } \\
100 \% \text { Sabic 520P }\end{array}$} & \multicolumn{2}{|c|}{$\begin{array}{l}\text { E-Modulus } \\
\text { (MPa) }\end{array}$} & \multicolumn{2}{|c|}{$\begin{array}{l}\text { Stress-max } \\
\text { (MPa) }\end{array}$} & \multicolumn{2}{|c|}{$\begin{array}{c}\text { Strain at break } \\
(\%)\end{array}$} & \multicolumn{2}{|c|}{$\begin{array}{l}\text { Impact resistance } \\
\left(\mathrm{kJ} / \mathrm{m}^{2}\right) \text { Unnotched }\end{array}$} \\
\hline & & 1185 & 52 & 43.1 & 0.6 & $>15$ & - & 90 & 4.3 \\
\hline 110220-I & 67\% Sabic 520P, 3\% Eastman G3015, 30\% Lowland fine & 2926 & 148 & 70.6 & 0.8 & 5.1 & 0.1 & 13 & 3 \\
\hline 110220-II & 67\% Sabic 520P, 3\% Eastman G3015, 30\% Lowland coarse & 3384 & 119 & 72.8 & 0.6 & 4.8 & 0.3 & 11.2 & 1.8 \\
\hline 110220-III & 67\% Sabic 520P, 3\% Eastman G3015, 30\% Lowland bottom & 3315 & 106 & 68.7 & 0.6 & 5.0 & 0.8 & 10.1 & 0.9 \\
\hline 110220-IV & 67\% Sabic 520P, 3\% Eastman G3015, 30\% Lowland middle & 3190 & 96 & 69.0 & 0.4 & 5.2 & 0.4 & 9.6 & 1.9 \\
\hline $110220-\mathrm{V}$ & 67\% Sabic 520P, 3\% Eastman G3015, 30\% Lowland top & 3263 & 146 & 69.5 & 0.2 & 4.7 & 0.2 & 9.4 & 0.8 \\
\hline 110220-VI & 67\% Sabic 520P, 3\% Eastman G3015, 30\% Highland fine & 2602 & 41 & 65.3 & 0.3 & 5.6 & 0.3 & 11.9 & 0.8 \\
\hline 110220-VII & 67\% Sabic 520P, 3\% Eastman G3015, 30\% Highland coarse & 2791 & 171 & 67.3 & 0.8 & 5.5 & 0.6 & 10.9 & 2.9 \\
\hline 110220-VIII & 67\% Sabic 520P, 3\% Eastman G3015, 30\% Highland bottom & 3014 & 45 & 67.6 & 0.3 & 5.0 & 0.3 & 13 & 1.3 \\
\hline 110220-IX & 67\% Sabic 520P, 3\% Eastman G3015, 30\% Highland middle & 3155 & 152 & 69.3 & 0.5 & 5.3 & 0.5 & 8.8 & 1.4 \\
\hline $110220-X$ & 67\% Sabic 520P, 3\% Eastman G3015, 30\% Highland top & 2923 & 299 & 67.5 & 0.8 & 5.7 & 0.2 & 9.4 & 1.7 \\
\hline
\end{tabular}




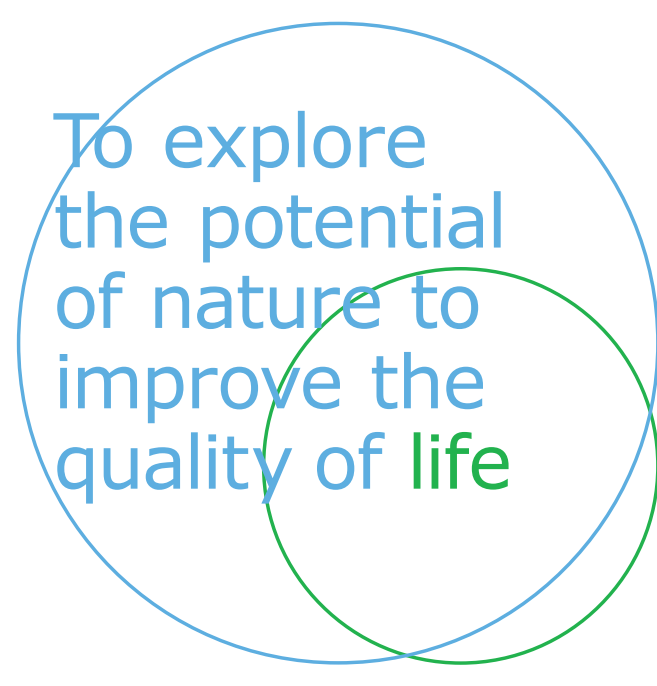

Wageningen Food \& Biobased Research Bornse Weilanden 9

6708 WG Wageningen

www.wur.nl/wfbr

info.wfbr@wur.nl

Rapport 2084

ISBN 978-94-6395-523-2

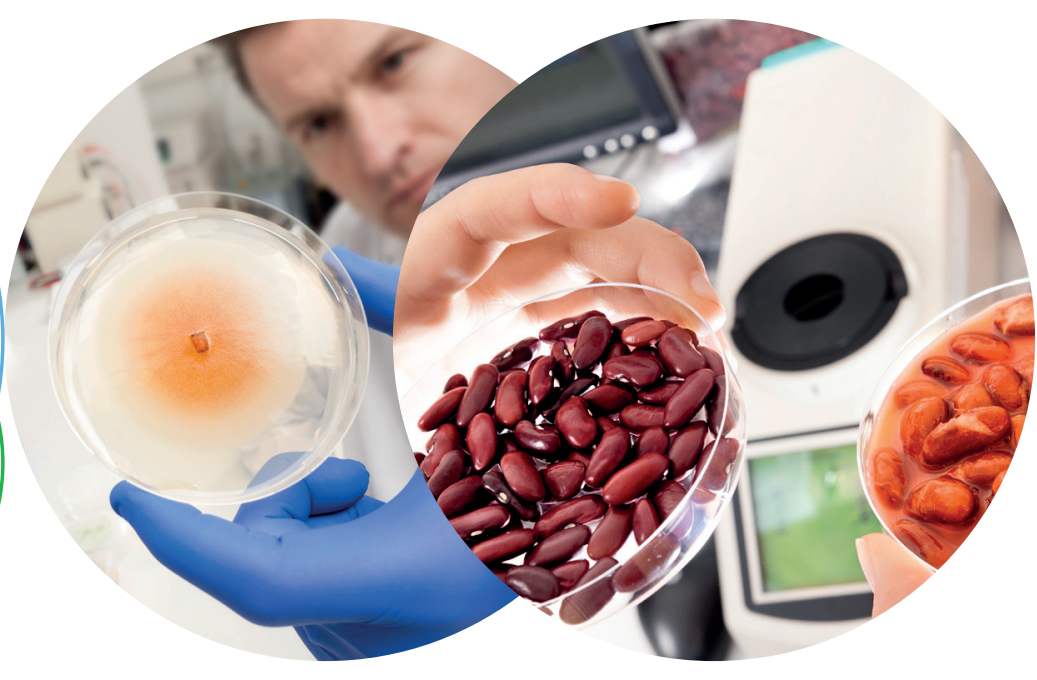

The mission of Wageningen University and Research is "To explore the potential of nature to improve the quality of life". Under the banner Wageningen University \& Research, Wageningen University and the specialised research institutes of the Wageningen Research Foundation have joined forces in contributing to finding solutions to important questions in the domain of healthy food and living environment. With its roughly 30 branches, 5,000 employees and 12,000 students, Wageningen University \& Research is one of the leading organisations in its domain. The unique Wageningen approach lies in its integrated approach to issues and the collaboration between different disciplines. 